\title{
Chevalerie et grivoiserie. Fabliaux de chevalerie, publiés, traduits, présentés et annotés par Jean-Luc Leclanche
}

\section{Maria Colombo Timelli}

\section{(2) OpenEdition Journals}

Édition électronique

URL : https://journals.openedition.org/studifrancesi/37192

DOI : 10.4000/studifrancesi.37192

ISSN : 2421-5856

Éditeur

Rosenberg \& Sellier

\section{Édition imprimée}

Date de publication : 15 décembre 2004

Pagination : 580-581

ISSN : 0039-2944

\section{Référence électronique}

Maria Colombo Timelli, « Chevalerie et grivoiserie. Fabliaux de chevalerie, publiés, traduits, présentés et annotés par Jean-Luc Leclanche », Studi Francesi [En ligne], 144 (XLVIII | III) | 2004, mis en ligne le 30 novembre 2015, consulté le 08 mai 2021. URL : http://journals.openedition.org/studifrancesi/37192 ; DOI : https://doi.org/10.4000/studifrancesi.37192

Ce document a été généré automatiquement le 8 mai 2021.

\section{cc) (†) $\odot$}

Studi Francesi è distribuita con Licenza Creative Commons Attribuzione - Non commerciale - Non opere derivate 4.0 Internazionale. 


\title{
Chevalerie et grivoiserie. Fabliaux de chevalerie, publiés, traduits, présentés et annotés par Jean-Luc Leclanche
}

\author{
Maria Colombo Timelli
}

\section{RÉFÉRENCE}

Chevalerie et grivoiserie. Fabliaux de chevalerie, publiés, traduits, présentés et annotés par Jean-Luc LECLANCHE, Paris, Champion, 2003 («Champion Classiques Moyen Age», 3), 283 pp.

1 Plus d'un recueil bilingue de fabliaux a vu le jour au cours de ces dernières années (cf. Fabliaux érotiques, éd. par Luciano Rossi, «Lettres gothiques», 1992; Fabliaux du Moyen Age, éd. par Jean Dufournet, Garnier-Flammarion, 1998), ce qui met à la portée des étudiants et des lecteurs non spécialistes, qui ne sauraient avoir recours au NRCF de Willem Noomen et Nico van den Boogard, des textes représentatifs du genre. Cette nouvelle édition de Jean-Luc Leclanche opère une coupe sur le corpus déclarée dès le titre: ce volume réunit en effet un nombre limité de fabliaux (cinq, mais au moins un autre volume est annoncé), centrés sur des protagonistes «bien nés» (p. VIII), des «chevaliers» selon la désignation la plus fréquente dans les textes. L'Introduction, synthétique mais sérieuse, met l'accent surtout sur le rapport conteur/ objet du rire / public qui s'instaure autour des récits, et souligne les éléments caractérisants de cette triade: le rôle créateur du récitant, qui ne cesse de modifier «son» texte, le rapport du naturel au dénaturé qui déclenche et légitime le rire, l'unicité du public des fabliaux et du reste de la littérature courtoise.

2 L'édition est fondée sur les manuscrits $\mathrm{F}$ (Le prêtre et le chevalier), D (Bérenger au long cul, Guillaume au faucon, Le fouteur), $\mathrm{G}$ (La mégère émasculée); elle est accompagnée, selon les 
habitudes de cette collection, par une traduction en prose publiée en regard, par des notes en bas de page où sont discutées certaines leçons, traductions, variantes, et d'un apparat critique final où sont réunies les leçons rejetées. Le dossier comprend aussi deux «Documents», soit deux récits complémentaires, pour lesquels l'étiquette de «fabliaux» est certainement discutable, mais qui apportent un éclairage significatif sur le rôle et les attentes des conteurs (Le Dit des Putains et des Jongleurs, édition fondée sur le ms. B), et sur la conception du genre «lai» au XIII siècle (Le Lai du Libertin, édition sur le ms. Paris BnF naf 1104). Le volume est complété par un Index des noms propres (pp. 237-243) intégrant les noms qui désignent des personnages (ami, chastelain, chevalier etc.) et les noms des divinités et allégories, et par un Glossaire assez riche (pp. 245-281): les deux donnent les références à chaque fabliau en abrégé. 